\title{
Arquiteturas Pedagógicas no Curso de Pedagogia a distância da UFRGS: análise de seus impactos
}

\author{
Ana Beatriz Michels ${ }^{1}$, Alexandre Ramos de Araújo ${ }^{2}$, Rosane Aragón ${ }^{3}$ \\ ${ }^{1}$ Secretaria de Desenvolvimento Tecnológico - Universidade Federal do Rio Grande do \\ Sul (UFRGS) \\ 90.040-020 - Porto Alegre - RS - Brasil \\ ${ }^{2}$ Faculdade de Educação \\ Universidade Federal do Rio Grande do Sul (UFRGS) - Porto Alegre - RS - Brasil \\ ${ }^{3}$ Faculdade de Educação \\ Universidade Federal do Rio Grande do Sul (UFRGS) - Porto Alegre - RS - Brasil \\ ana.michels@ufrgs.br, alexandreraraujo@yahoo.com.br, \\ rosane.aragon@gmail.com
}

\begin{abstract}
This article aims to analyze the process of appropriation and use of pedagogical architectures, both by teachers and tutors as by the students, in conjunction with the methodological approach of the Faculty of Distance Education UFRGS (PEAD). The empirical data of this study consist of articles published in journals, proceedings and book chapters, were analyzed with the support of NVivo software from the perspective of content analysis. The results show that there is a consistency between the proposed PEAD and the training of student teachers, line which provided an opportunity to (re)construction of knowledge and a reframing in teaching practices in the classroom studentteachers.
\end{abstract}

Key words: Pedagogical Architectures, Distance Education, Teacher Training.

Resumo. Este artigo tem como finalidade analisar o processo de apropriação $e$ utilização de arquiteturas pedagógicas, tanto por parte dos professores e tutores quanto por parte dos alunos, articulado com a proposta metodológica do curso de Pedagogia a Distância da UFRGS (PEAD). Os dados empíricos desse estudo, composto por artigos publicados em periódicos, anais e capítulos de livros, foram analisados com o apoio do software NVIVO, na perspectiva da análise de conteúdo. Os resultados mostram que existe uma coerência entre a proposta do PEAD e a formação dos alunos-professores, consonância que oportunizou a (re) construção constante de conhecimento e uma ressignificação nas práticas pedagógicas em sala de aula dos alunos-professores.

Palavras-chave: Arquiteturas Pedagógicas, Educação a Distância, Formação de Professores. 


\section{Introdução}

A educação tem um papel fundamental de formar os cidadãos para uma sociedade que está em constante mudança, sendo necessário um entendimento dos reais desafios dessa sociedade. Mesmo que existam muitos desafios a serem percorridos, se a base da educação não estiver fortalecida, o Brasil está fadado a manter os dados educacionais de baixo nível [Gatti in Lopes, 2015]. E essa base refere-se à educação básica e a forma pela qual os professores são formados.

Em relação à formação dos professores, os cursos na modalidade de educação a distância $(\mathrm{EaD})$ tem crescido, sendo que o curso de Pedagogia ocupa o primeiro lugar em matrículas na modalidade $\mathrm{EaD}$ (44,5\% do total de matrículas), como mostram os dados do INEP de 2013 [Brasil, 2013]. Essa expansão deixa um alerta para questões necessárias à garantia da qualidade dos cursos, sendo elas de cunho pedagógico, tecnológico e logístico. Muitos dos cursos estão distantes da realidade da sala de aula que, com as mudanças constantes nas formas de aprender e ensinar, não preparam os futuros professores para dialogarem com essa nova realidade [Lopes, 2015].

A formação dos professores precisa ser pensada "[...] a partir da função social própria à escolarização - ensinar às novas gerações o conhecimento acumulado e consolidar valores e práticas coerentes com nossa vida civil" [Gatti, 2010]. Nesse sentido, os Referenciais de Qualidade para a EaD [Brasil, 2007] apresentam uma perspectiva de aprendizagem que enfatiza modelos de pedagogias abertas e de construção da aprendizagem em rede. Esses modelos se adequam a uma concepção construtivista de cursos $\mathrm{EaD}$ e uma alternativa é tomar como base os pressupostos e as estratégias didáticas das arquiteturas pedagógicas, que são definidas como estruturas de aprendizagem constituídas por diferentes componentes tecnológicos e pedagógicos [Nevado, Carvalho e Menezes, 2007].

O curso de Pedagogia a distância da Universidade Federal do Rio Grande do Sul (PEAD/UFRGS) - realizado de 2006 a 2010 - construiu seu projeto pedagógico nos moldes da concepção construtivista. Para compreender o curso e seus impactos na formação dos professores, está sendo realizada uma pesquisa que busca analisar o que as publicações revelam acerca das concepções e práticas pedagógicas do PEAD/UFRGS. Num primeiro momento, estão sendo analisados apenas os artigos em periódicos e capítulos de livros, num total de cinquenta publicações que se referem ao Curso. A análise de dados está sendo realizada considerando-se nove categorias, que foram definidas a partir dos pressupostos pedagógicos do curso e da fundamentação teórica da pesquisa. Neste artigo será avaliado apenas o impacto da categoria 'Arquiteturas Pedagógicas', pelo fato desta ter norteado a concepção do curso e terem sido referenciada nas publicações dos periódicos. Para compreender a proposta do curso e o que as publicações revelam acerca do mesmo, na seção 2 é apresentado o projeto pedagógico do PEAD/UFRGS e na seção 3 as arquiteturas pedagógicas. A seção 4 relata a metodologia da pesquisa - coleta e análise dos dados - e, por fim, a seção 5 apresenta as considerações finais. 
V Congresso Brasileiro de Informática na Educação (CBIE 2016)

Anais dos Workshops do V Congresso Brasileiro de Informática na Educação (CBIE 2016)

\section{Projeto Pedagógico do PEAD}

O projeto pedagógico do PEAD propõe uma formação que seja caracterizada como um processo autônomo, buscando superar a distância existente, na maioria dos cursos de Pedagogia, entre a teorização de práticas educacionais e a vivência destas práticas em sala de aula. Tal diferenciação do PEAD para outros cursos de Pedagogia foi necessária, principalmente, por dois motivos: (i) os alunos do curso foram professores em exercícios da rede pública sem formação específica e (ii) o curso buscou considerar as experiências de vida e profissionais dos professores, garantindo qualidade na formação.

O PEAD foi planejado com uma perspectiva de educação, ao mesmo tempo, inicial e continuada, buscando integrar a experiência do aluno, como professor, seu cotidiano em sala de aula e a educação universitária que integra o ensino, pesquisa e extensão. A primeira edição do curso atendeu 400 alunos e se desenvolveu em nove semestres letivos, abrangendo: (i) atividades formativas (interdisciplinas de caráter teórico-prático, seminários integradores com práticas pedagógicas, participação na realização de pesquisas, participação em grupos cooperativos de estudos); (ii) estágio de docência supervisionado; (iii) atividades teórico-práticas de aprofundamento em áreas específicas de interesse dos alunos, por meio da iniciação científica, da extensão e da monitoria.

No PEAD, a grade curricular foi organizada em eixos temáticos que tem o objetivo de articular as atividades do semestre, mostrando a direção do foco da abordagem em todas as atividades. Cada eixo articulador corresponde a um semestre letivo, sendo desdobrados em interdisciplinas - campo de abordagem de um tema mais amplo, apresentando várias possibilidades de enfoque temático. Para garantir esta interdisciplinaridade e a ligação com as experiências de cada aluno em sala de aula, cada eixo possui uma interdisciplina designada Seminário Integrador - atividades relacionadas com todas as interdisciplinas do respectivo eixo.

Um dos objetivos do Projeto Pedagógico é que os materiais didáticos atendam professoras em serviço, isto é, alunas que possuem experiência na docência das séries iniciais do Ensino Fundamental ou Educação Infantil. Os materiais devem apresentar as seguintes características: (a) imersão das alunas professoras na resolução de problemas; (b) condução à construção de novos conhecimentos; (c) incentivo à busca de soluções criativas; (d) contextualização da realidade local; (e) proporcionar a troca de ideias entre os sujeitos envolvidos no curso; (f) elaboração de projetos de aprendizagem possíveis de serem desenvolvidos pelas alunas professoras em suas classes.

A aplicabilidade destes materiais deve ultrapassar a reprodução de atividades, gerando novas práticas e qualificando as alunas-professoras na utilização das tecnologias digitais para a construção do conhecimento de seus alunos.

\section{Arquiteturas Pedagógicas na Formação de Professores}

O uso das tecnologias digitais na educação, e mais precisamente na aprendizagem online, tem crescido e contribuído com mudanças nos ambientes de ensino e aprendizagem [Palloff e Pratt, 2015], oportunizando uma maior interação entre os atores envolvidos nesse processo. Porém, mesmo que as tecnologias digitais "criam formas inovadoras de interagirmos uns com os outros e de acesso ao saber e de produção do conhecimento" 
[Ferreira e Silva, 2014], ainda existem modelos de EaD em que há uma primazia para processos de ensino [Belloni, 2008].

Devido a constante mudança da sociedade e das tecnologias digitais, a formação dos professores incluiu saberes conexos, como o uso e manejo dos recursos tecnológicos [Leite, Genro e Braga, 2011]. Nessa formação, as tecnologias digitais podem aprimorar as estratégias pedagógicas, dando suporte às reconstruções dos alunos-professores, promovendo uma mudança de paradigma do modelo behaviorista para uma abordagem mais construtivista, com foco no aluno e na cooperação entre eles [Costa et al, 2013]. É nesse contexto que se inserem as arquiteturas pedagógicas, que são "[...] estruturas de aprendizagem realizadas a partir da confluência de diferentes componentes: abordagem pedagógica, software educacional, internet, inteligência artificial, EAD, concepção de tempo e de espaço" [Nevado, Carvalho e Menezes, 2007].

Muito além da união de diferentes ferramentas, as arquiteturas pedagó gicas contemplam a intenção pedagógica, entendendo que o processo de aprendizagem está assentado no debate, na troca, nas interações [Nevado, Carvalho e Menezes, 2007], provocando desequilíbrios nas certezas provisórias dos alunos e dando suporte para suas reconstruções. Nesse processo, os próprios alunos escolhem os caminhos que pretendem percorrer durante seu processo de aprendizagem, podendo percorrê-los de forma individual ou coletivamente. Nesse processo de escolha de caminhos é que as arquiteturas pedagógicas "[...] funcionam metaforicamente como mapas ao mostrar diferentes direções para se realizar algo [Nevado, Carvalho e Menezes, 2007].

As inovações pedagógicas inseridas na construção de arquiteturas pedagógicas não estão relacionadas apenas às práticas criativas com o uso das tecnologias digitais, mas envolvem também uma teoria explicitada e uma sistematização da metodologia [Nevado, Carvalho e Menezes, 2007]. A confluência destes três elementos oportuniza o desenvolvimento de arquiteturas pedagógicas mais flexíveis e adaptáveis a diferentes contextos. Dessa forma, passa a ser uma grande aliada dos professores em sala de aula, que podem utilizá-la de forma individual e integrada com outras disciplinas, estimulando a (re)construção constante de conhecimento por parte dos alunos e professores.

\section{Coleta e Análise dos dados}

As discussões presentes neste artigo são um recorte de um estudo mais abrangente que busca analisar o que as publicações apresentam acerca das concepções e práticas pedagógicas do PEAD. A construção do instrumento de coleta de dados - artigos publicados e capítulos de livros - foram tratados sob o referencial da análise de conteúdo segundo Bardin (2009), pois, além de interpretar os dados, leva-se em consideração o contexto do objeto em estudo.

O levantamento das publicações foi realizado por meio de palavras-chave pesquisadas nas seguintes bases de dados: LUME (UFRGS), SciELO, Google Acadêmico, CAPES. A busca ficou restrita às publicações escritas sobre o Curso (PEAD), considerando-se os objetivos do estudo. Após o levantamento, foi elaborada uma lista única das referências encontradas e, em seguida, estas foram submetidas à leitura dos resumos para a classificação dos textos, onde foram selecionados cinquenta artigos e capítulos de livros. O tratamento inicial do material foi realizado com o auxílio 
V Congresso Brasileiro de Informática na Educação (CBIE 2016)

Anais dos Workshops do V Congresso Brasileiro de Informática na Educação (CBIE 2016)

de um software adequado à análise qualitativa de dados - o QSR Nvivo -, através de uma interpretação inicial e categorização dos dados.

Dentre as nove categorias do projeto de pesquisa, este estudo aborda apenas a categoria 'Arquiteturas Pedagógicas', que busca analisar o processo de construção, aplicação e apropriação de estratégias educacionais/pedagógicas com o uso de ferramentas tecnológicas, tanto por parte dos professores e tutores quanto por parte dos alunos articulados com a proposta metodológica do curso. Esta categoria foi encontrada em vinte e quatro publicações e, para responder à questão da pesquisa, a categoria está dividida em duas subcategorias, sendo elas: (1) Descrição do suporte computacional utilizado no desenvolvimento das arquiteturas pedagógicas; (2) Reflexões acerca do uso e da importância das arquiteturas pedagógicas no decorrer do curso.

As subcategorias envolvem, respectivamente, uma visão das ferramentas tecnológicas utilizadas, os resultados do uso das arquiteturas pedagógicas na formação dos alunos-professores (visão interna do curso) e a sua importância nas práticas pedagógicas em sala de aula dos alunos-professores (visão além do curso).

A Tabela 1 apresenta o total de artigos que abordaram cada uma das subcategorias, bem como o total de referências/extratos extraídos dos artigos.

Tabela 1: Total de artigos e referências relacionados a cada subcategoria.

\begin{tabular}{|l|c|c|}
\hline \multicolumn{1}{|c|}{ Subcategorias } & Artigos & Referências \\
\hline $\begin{array}{l}\text { 1. Descrição do suporte computacional utilizado no desenvolvimento } \\
\text { das arquiteturas pedagógicas }\end{array}$ & 18 & 61 \\
\hline $\begin{array}{l}\text { 2. Reflexões acerca do uso e da importância das arquiteturas } \\
\text { pedagógicas no decorrer do curso }\end{array}$ & 24 & 112 \\
\hline
\end{tabular}

Fonte: NVivo 10.

A seguir são abordadas cada uma das subcategorias.

\subsection{Subcategoria 1 - Descrição do suporte computacional utilizado no desenvolvimento das arquiteturas pedagógicas}

Durante o planejamento e desenvolvimento de uma arquitetura pedagógica, a tecnologia digital é um elemento essencial, sendo necessário avaliar as possibilidades e restrições de cada ferramenta considerada, tendo em vista a suas possibilidades de oferecer suporte, seja isoladamente ou em composição com outras.

Para exemplificar, o extrato abaixo descreve uma ferramenta que na primeira versão não alcançou seu propósito inicial, pois a estrutura do objeto de aprendizagem (OA) primou por um modelo behaviorista de educação, não oportunizando uma aprendizagem em rede, conforme almeja o projeto pedagógico do PEAD e os Referenciais de Qualidade para a EaD (MEC, 2007).

"Na primeira versão desenvolvida deste $O A$, tinha-se como objetivo aproximar os alunos das disciplinas de Prática de Ensino para o uso da informática na educação. No entanto, o OA caracterizou-se dentro de uma estrutura pedagógica linear e fragmentada que não atendia à proposta inicial por estar refletindo uma prática instrucionista de educação. [...] No segundo protótipo importantes melhorias foram realizadas. A estrutura utilizada em forma de Blog Pedagógico 
V Congresso Brasileiro de Informática na Educação (CBIE 2016)

Anais dos Workshops do V Congresso Brasileiro de Informática na Educação (CBIE 2016)

possibilitou um avanço em termos de design de interação. [Boll, Carvalho e Meirelles in Nevado, Carvalho e Menezes, 2009]

O objetivo do OA foi de aproximar os alunos-professores com o uso da informática na educação. No momento que o objetivo inicial não foi alcançado, foi necessário repensar as ferramentas tecnológicas utilizadas e as formas de aplicação. A partir dessa reflexão acerca do desenvolvimento e uso do OA, o objeto foi reconstruído, utilizando-se uma estrutura de blog pedagógico e aproximando-se de um modelo interacionista, o que oportunizou uma maior interação entre os alunos-professores.

A ferramenta blog foi usada durante todo o PEAD, compondo diferentes arquiteturas, como o "portfólio de aprendizagem", no qual os alunos-professores postavam suas reflexões acerca das atividades realizadas dentro de cada eixo temático. $\mathrm{O}$ extrato abaixo reforça sua importância.

"Os portfólios de aprendizagem foram construidos numa ferramenta virtual de escrita colaborativa denominada Blog, o qual é uma pagina na web cuja estrutura permite a atualização rápida e fácil através de textos, que são chamados de postagens. Estes textos são organizados de forma cronológica inversa, também é composto por imagens, sons e links. Cada aluno tinha seu próprio espaço de construção e os tutores podiam registrar intervenções, dicas, sugestões, críticas. Este processo era aberto e público, e os demais colegas podiam interferir no diálogo, se desejassem." [Martins e Passerino, 2013]

Os recursos tecnológicos disponíveis no blog, como a inserção de imagens, sons e links nas postagens, bem como a proposta de aplicação no PEAD, oportunizaram aos alunos-professores expressarem seus conhecimentos de formas diversas. Além disso, pelo fato do blog ser uma ferramenta aberta, foi possível a realização de comentários dos colegas e da equipe docente em cada relato postado.

Outra ferramenta bastante utilizada durante o PEAD foi o PBworks, que é um espaço de construção colaborativa. Buscando manter um diálogo entre professores e tutores e os alunos-professores, além das ferramentas blog e PBWorks, no curso também foram utilizadas o ambiente ROODA, fóruns, e-mail, messenger. Cada ferramenta tinha uma aplicação específica, mas o intuito maior era oferecer diferentes recursos para 'diminuir' a distância entre os participantes.

"O trabalho a distância foi realizado com a participação intensiva dos tutores e professores, buscando manter um diálogo continuado, complementados pelo oferecimento de sugestões e encaminhamentos necessários ao prosseguimento dos trabalhos e às reconstruções necessárias em cada caso. Para viabilizar esta contínua interlocução, foram utilizadas diversas ferramentas de apoio ao trabalho cooperativo, tais como o ambiente ROODA2, blogs, wikis, fóruns e e-mail. Uma forma de gerar maior aproximação e melhorar as interações foi obtida com ferramentas ágeis de comunicação interpessoal como, por exemplo, o sistema Messenger (MSN) de troca de mensagens." (ZIEDE, ARAGON, MENEZES, CHARCZUK, 2012, p. 03)

Destarte, as ferramentas utilizadas no PEAD foram escolhidas pela adequação dos seus procedimentos aos objetivos do PEAD. Os relatos apresentados acima indicam que as ferramentas utilizadas nas arquiteturas pedagógicas foram apropriadas para alcançar o propósito de promover a construção do conhecimento e o estabelecimento de redes de aprendizagem no decorrer do curso.

\subsection{Subcategoria 2 - Reflexões acerca do uso e da importância das arquiteturas pedagógicas no decorrer do curso}


V Congresso Brasileiro de Informática na Educação (CBIE 2016)

Anais dos Workshops do V Congresso Brasileiro de Informática na Educação (CBIE 2016)

O principal motivo das arquiteturas pedagógicas serem criadas, aplicadas e reavaliadas constantemente no PEAD foi o de alcançar - e enriquecer - a proposta pedagógica do curso, oportunizando a aprendizagem em rede. A abordagem curricular, desenvolvida no modelo de arquiteturas pedagógicas, visou possibilitar que os alunos-professores refletissem sobre suas aprendizagens e, além disso, estabelecessem uma relação entre suas aprendizagens e suas práticas pedagógicas, conforme mostra o extrato a seguir.

"Este portfólio teve seu ponto culminante no Eixo 9 quando as professoras-alunas foram convidadas a revisitar os registros dos semestres anteriores e realizar uma ampla reflexão sobre as suas aprendizagens e sobre o entrelaçamentos das temáticas exploradas no decorrer do curso, buscando estabelecer uma relação entre as aprendizagens e as transformações em suas práticas pedagógicas." [Aragon, Menezes e Novak, 2013]

As transformações nas práticas pedagógicas dos alunos-professores foram ocorrendo na medida em que eles puderam vivenciar e refletir sobre diferentes arquiteturas enquanto alunos. Conforme relato abaixo, tanto a inclusão digital quanto a virtualização do conhecimento proporcionado pelo PEAD aconteceram durante as atividades propostas das arquiteturas pedagógicas.

"Exigiu dos alunos-professores usarem as tecnologias de rede projetando a solução de problemas para as questões levantadas nas áreas disciplinares. Isso resultou em possibilidades de aplicação tangíveis do ponto de vista pedagógico em suas práticas cotidianas de sala de aula, porque é integrado ao mapa conceitual e prático em cada área disciplinar. É neste ponto que se destacam a virtualização do conhecimento e a inclusão digital. Elas acontecem no interior de arquiteturas pedagógicas pensadas para a formação de professores em serviço." [Grasel e Carvalho, 2013]

O portfólio de aprendizagem teve uma influência positiva na formação contínua dos alunos-professores, pois estes, semanalmente, postavam algumas ideias, práticas ou reflexões que eram suscitadas por suas próprias experiências vividas, tanto como alunos quanto como professores. Essas postagens também relacionavam suas práticas com as teorias estudadas durante o PEAD, oportunizando uma construção teórico-prática.

“No PEAD, as professoras-alunas usam o blog como "Portfólio de Aprendizagens" no qual relacionam suas práticas com as teorias que estão estudando. Elas colocam marcadores com as interdisciplinas e os colegas, tutores e professores comentam criando assim uma rede de interações." [Charczuk e Ziede, 2010]

Os alunos do curso, por serem professores em serviço, foram estimulados a replicarem em suas salas de aula as arquiteturas pedagógicas utilizadas no curso. Além disso, também foram incentivados a criarem materiais pedagógicos digitais para serem aplicados em suas práticas docentes, como mostra o relato abaixo.

"No PEAD, as alunas são incentivadas a criarem materiais pedagógicos digitais para o trabalho com os seus alunos. Já é possível observar várias iniciativas de produção de materiais pedagógicos para aplicação com alunos dos Anos Iniciais do Ensino Fundamental. Essas iniciativas vêm mostrando que as alunas-professoras, ao vivenciarem o uso das tecnologias aliado às metodologias construtivistas, no âmbito do curso de formação, tendem a replicar essas formas de trabalho na sua prática docente." [Quadros e Marques, 2013]

As atividades propostas no PEAD sempre almejaram fortalecer a aprendizagem em rede e, nesse processo, a autonomia e a cooperação são competências essenciais a serem desenvolvidas pelos alunos-professores. Durante o Seminário Integrador em um dos polos do curso, além dos alunos participarem das atividades, um deles teve a ideia de criar uma página no Wiki que, no decorrer dos semestres, foi sendo atualizada por seus colegas de turma, como mostra o extrato abaixo. 
V Congresso Brasileiro de Informática na Educação (CBIE 2016)

Anais dos Workshops do V Congresso Brasileiro de Informática na Educação (CBIE 2016)

"A autonomia e cooperação que buscávamos desenvolver manifestaram-se concretamente no Eixo $V$, quando uma cursista abriu no wiki do polo uma página "Para quem perdeu a bússola!", na qual fazia sínteses arrolando as atividades que deveriam ser completadas para as diferentes interdisciplinas do semestre, seus prazos, indicações do que deveria ser lido, o que deveria resultar da leitura e links para onde estavam os materiais. Essas sínteses, com o tempo, começaram a ser atualizadas também por outras colegas, num claro processo de operação conjunta." [Costa e Magdalena, 2013]

Outra arquitetura, com base no uso do blog, foi utilizada no final do curso para preparar os alunos-professores no planejamento de seus trabalhos de conclusão do curso. O relato abaixo mostra essa proposta, na qual os alunos revisitaram a sua trajetória de aprendizagem durante o curso.

"Durante a realização do nono semestre do curso, quando os alunos realizavam os estudos que culminaria com a produção do Trabalho de Conclusão de Curso (TCC) foi proposta uma variação da arquitetura. A atividade estruturante consistiu na postagem de reflexões baseadas em uma revisita aos registros dos semestres anteriores, para cada um dos quais foi solicitado que fizessem uma ou mais postagens, tentando estabelecer ligações entre o que estudaram em um dado semestre e suas conexões com o prosseguimento do curso. [...]” [Menezes et al, 2013]

As publicações acerca do uso de arquiteturas pedagógicas no PEAD indicam que os resultados alcançados na formação dos alunos-professores correspondem aos objetivos propostos no projeto pedagógico do curso. A análise dos dados mostra um crescimento gradual de engajamento, autonomia e cooperação dos - e entre os - alunosprofessores, sinalizando o alcance do objetivo de construção de redes de aprendizagem, bem como a construção de conhecimentos teórico-práticos que deram suporte a reconstrução de algumas arquiteturas pedagógicas para utilização em suas salas de aula.

\section{Considerações Finais}

Buscando responder à questão norteadora - o que as publicações revelam acerca das concepções e práticas pedagógicas do curso PEAD/UFRGS, a partir do uso de arquiteturas pedagógicas na formação dos alunos-professores - a análise dos dados mostrou indicadores de impacto do uso de arquiteturas pedagógicas no PEAD, sendo eles:

- as arquiteturas pedagógicas foram aplicadas com o propósito de oportunizar a construção de espaços de aprendizagem por parte dos alunos-professores;

- as ferramentas utilizadas foram avaliadas constantemente durante o curso, desafiando os alunos-professores a construírem conhecimento com base em suas vivências;

- a forma como as arquiteturas pedagógicas foram propostas e (re)propostas nas interdisciplinas, proporcionaram uma (re)avaliação constante das aprendizagens dos alunos-professores;

- houve um crescimento constante de engajamento, autonomia e cooperação dos - e entre os - alunos-professores;

- construção de uma aprendizagem em rede a partir da participação dos alunosprofessores nas atividades propostas no curso, observadas pelos relatos de criação de novas atividades/debates pelos próprios alunos-professores; 
- construção de conhecimento teórico-prático pelos alunos-professores e possibilidades de replicação e construção de arquiteturas pedagógicas a serem utilizadas com seus alunos.

Em síntese, a proposta pedagógica do PEAD, com base no uso de arquiteturas pedagógicas abertas e flexíveis, conforme mostram as publicações analisadas, atuou positivamente na formação dos alunos-professores, favorecendo a construção de conhecimento em rede e apresentando repercussões nas práticas pedagógicas, com destaque para o crescente uso das tecnologias digitais com os seus alunos.

\section{Referências}

ARAGON, R.; MENEZES, C. S.; NOVAK, S. (2013) Curso de graduação licenciatura em pedagogia na modalidade a distância PEAD): concepção, realização e reflexões. In: Revista Novas Tecnologias na Educação, CINTED - UFRGS, vol. 1, no. 02.

BARDIN, L. (2009) Análise de Conteúdo. Lisboa, Portugal; Edições 70, LDA.

BELLONI, M. L. (2008). Educação a distância. 5. ed. São Paulo: Autores Associados.

BOLL, C. I.; CARVALHO, M. J. S.; MEIRELlES, M. (2007) Hipermidi(d)áticos: a necessária discussão entre formação de professores e objetos de aprendizagem em educação à distância. In: NEVADO. R. A.; CARVALHO, M. J. S. e MENEZES, C. S. (Org.). Aprendizagem em rede na Educação a Distância: estudos e recursos para formação de professores. Editora Ricardo Lenz, p. 47 - 64.

BRASIL. MEC. (2007) Referenciais de Qualidade para a educação a distância. Brasília: Secretaria de Educação a Distância.

BRASIL. MEC. (2013) Censo da educação superior. Brasília: Instituto Nacional de Estudos e Pesquisas Educacionais Anísio Teixeira.

CHARCZUK. S. B.; ZIEDE, M. K. L. (2010) Blogs como Portfólios de Aprendizagem: a construção de conhecimentos a partir da interação entre tutores e alunos. In: Revista Novas Tecnologias na Educação, CINTED - UFRGS, vol. 8, no. 01.

COSTA, I. E. T.; MAGDALENA, B. C. (2013) Seminário Integrador, no polo de Alvorada: um estudo de caso. In: Revista Novas Tecnologias na Educação, CINTED - UFRGS, vol. 11, no. 02.

COSTA, L. B; et al (2013) Pedagogical architectures and web resources in the teachinglearning of programming. In: Nuevas Ideas en Informática Educativa, TISE.

FERREIRA, A. A.; SILVA, B. D. (2014) Comunidade de prática on-line: uma estratégia para o desenvolvimento profissional dos professores de História. In: Educação em Revista, vol.30, no.1, Belo Horizonte.

GATTI, B. A. (2010) Formação de professores no Brasil: características e problemas. In: Educação \& Sociedade. Campinas, v. 31, n. 113, p. 1355-1379.

GRASEL, P.; CARVALHO, M. J. S. (2013) Formação de professores: práticas em educação a distância. In: X Congresso Brasileiro de Ensino Superior a Distância, ESUD. 
V Congresso Brasileiro de Informática na Educação (CBIE 2016)

Anais dos Workshops do V Congresso Brasileiro de Informática na Educação (CBIE 2016)

LEITE, D; GENRO, M. E. H; BRAGA, M. S. (2011) Inovações pedagógicas e demandas ao docente na universidade. In: LEITE, D; GENRO, M. E. H; BRAGA, M. S. (org). Inovação e pedagogia universitária. Porto Alegre: Editora da UFRGS, p. $19-39$.

LOPES, M. (2015) Desafios e caminhos para a formação de professores no Brasil. In: Porvir. Disponível em: http://porvir.org/desafios-caminhos-para-formacao-deprofessores-brasil/. Acesso em 08 de junho de 2016.

MARTINS, M. C. C.; PASSERINO, L. M. (2013) Portfólio de aprendizagem como espaço de construção do conhecimento. In: Revista Novas Tecnologias na Educação, CINTED - UFRGS, vol. 11, no. 2.

MENEZES, C. S. et al. (2013) Arquiteturas pedagógicas para a aprendizagem em rede no contexto do seminário integrador. In: Revista Novas Tecnologias na Educação, CINTED - UFRGS, vol. 11, no. 02.

NEVADO. R. A.; CARVALHO, M. J. S. e MENEZES, C. S. (Org.). (2007) Aprendizagem em Rede na Educação a Distância: Estudos e Recursos para Formação de Professores. Porto Alegre: Ricardo Lenz.

PALlOFF, R. M.; PRATT, K. (2013) Lições da Sala de Aula Virtual. 2 ed. Porto Alegre: Penso.

QUADROS, A. M.; MARQUES, T. B. I. (2013) Inovação ou novidade? Práticas educativas e tecnologias digitais de rede. In: Revista Novas Tecnologias na Educação, CINTED - UFRGS, vol. 11, no. 02. 